\title{
Chemotherapy alone is an alternative treatment in treating localized primary ocular adnexal lymphomas
}

\author{
Wei-Li Ma ${ }^{1,2,5,6,7}$, Ming $\mathrm{Yao}^{3}$, Shu-Lang Liao ${ }^{4}$, Jih-Luh Tang ${ }^{3}$, Yao-Ching Wang ${ }^{8}$, \\ Sung-Hsin Kuo $\mathrm{K}^{2,5,6,7}$ and Ann-Lii Cheng ${ }^{2,3,5,6,7}$ \\ ${ }^{1}$ Department of Oncology, National Taiwan University Hospital, Yun-Lin Branch, Yun-Lin, Taiwan \\ ${ }^{2}$ Department of Oncology, National Taiwan University Hospital and National Taiwan University College of Medicine, Taipei, \\ Taiwan \\ ${ }^{3}$ Division of Hematology, Department of Internal Medicine, National Taiwan University Hospital, Taipei, Taiwan \\ ${ }^{4}$ Department of Ophthalmology, National Taiwan University Hospital, Taipei, Taiwan \\ ${ }^{5}$ National Taiwan University Cancer Center, National Taiwan University College of Medicine, Taipei, Taiwan \\ ${ }^{6}$ Graduate Institute of Oncology, National Taiwan University College of Medicine, Taipei, Taiwan \\ ${ }^{7}$ Cancer Research Center, National Taiwan University College of Medicine, Taipei, Taiwan \\ ${ }^{8}$ Department of Biomedical Imaging and Radiological Science, College of Health Care, China Medical University, Taichung, \\ Taiwan
}

Correspondence to: Sung-Hsin Kuo, email: shkuo101@ntu.edu.tw

Keywords: ocular adnexal lymphomas, chemotherapy, radiotherapy, event-free survival, overall survival

Received: July 29, 2016

Accepted: May 29, 2017

Published: June 15, 2017

Copyright: Ma et al. This is an open-access article distributed under the terms of the Creative Commons Attribution License 3.0 (CC BY 3.0 ), which permits unrestricted use, distribution, and reproduction in any medium, provided the original author and source are credited.

\section{ABSTRACT}

This study investigated the treatment efficacy and long-term adverse effects of various treatment modalities for primary ocular adnexal lymphomas (POALs). We retrospectively reviewed 107 patients who received first-line chemotherapy, radiotherapy, and other treatment modalities from 1990 to 2015. Nighty-three (87\%) patients were diagnosed with mucosa-associated lymphoid tissue (MALT) lymphoma, with the orbit being the most common site (49 patients, 46\%). Among 91 patients with stage I-IIE1 disease, 26 underwent chemotherapy, 34 underwent radiotherapy, and 31 received other treatment modalities. For chemotherapy, radiotherapy, and other treatment modalities, the 5-year event-free survival (EFS) rates were $\mathbf{9 0 . 0 \%}$, $89.7 \%$, and $85.8 \%$ and the 5-year overall survival (OS) rates were $100 \%, 90.4 \%$, and $\mathbf{8 7 . 5} \%$, respectively. Moreover, among 80 patients with stage I-IIE1 MALT Iymphoma, the complete remission, 5-year EFS and OS rates were not significantly different between patients receiving chemotherapy and those receiving radiotherapy. Among 16 patients with stage IIE2-IVE disease, the 5-year EFS rates for chemotherapy alone $(n=11)$ and combined radiotherapy and chemotherapy $(n=5)$ were $61.7 \%$ and $\mathbf{8 0} \%$, respectively, whereas the 5 -year os rate for both groups was $80.0 \%$. Neutropenia (15.2\%) was the most common side effect in patients who received chemotherapy, whereas cataract $(16.3 \%)$ was the most common late sequela in patients who received radiotherapy. Multivariate analysis revealed that old age $(>60 \mathrm{y})$ and an advanced stage (stage III/IV) were prognostic factors for poor OS. Our results indicate that chemotherapy yields satisfactory disease control and fewer side effects, and acts as an alternative therapy for patients with localized POALs. 


\section{INTRODUCTION}

Primary ocular adnexal lymphomas (POALs) present in the orbit, extraocular muscle, eyelids, lacrimal gland, or conjunctiva and represent up to $1 \%$ of all nonHodgkin lymphomas [1, 2]. Mucosa-associated lymphoid tissue (MALT) lymphoma is the most common type. In addition, diffuse large B-cell lymphoma (DLBCL) with or without histological evidence of MALT origin or follicular lymphoma (FL) has been reported $[3,4]$. Treatment strategies for localized POALs remain controversial. Although a proportion of patients with a histologic diagnosis of low-grade MALT lymphoma of POAL (MALT-POAL) can be treated using doxycycline (conventionally used for eradicating Chlamydia psittaci $[5,6])$, local radiotherapy is the standard first-line treatment for patients with MALT-POAL in Western countries [7]. Previous studies have demonstrated that radiotherapy provides an immediate effect and excellent local control of indolent POALs, including MALT lymphoma and FL; however, late recurrences have been reported [8-10]. Notably, local radiotherapy to the ocular adnexal areas possibly causes acute and late side effects, such as cataract, dry eyes, keratitis, and retinopathy $[11,12]$.

In contrast to local radiotherapy, systemic chemotherapy with a single alkylating agent (chlorambucil) or a combination of cyclophosphamide, vincristine, and prednisolone (CVP) has been administered to treat localized (stage IE to IIE1) MALT-POAL, with a reported complete remission (CR) rate of approximately $75 \%[13,14]$. In addition to systemic chemotherapy, studies have reported that rituximab monotherapy serves as the firstline or second-line therapy for low-grade POALs (included MALT lymphoma and FL), providing a CR rate of approximately $30 \%-50 \%$ and disease-free status [15-18]. However, the long-term clinical outcomes of combined chemotherapy and rituximab in patients with localized POALs have rarely been described.

In this study, we aimed to identify the clinical outcomes of frontline systemic chemotherapy with or without rituximab in patients with all POAL stages. In addition, we compared the treatment efficacy and longterm adverse effect of systemic chemotherapy (with and without rituximab) with those of radiotherapy alone in patients with localized POALs.

\section{RESULTS}

\section{Patient characteristics and treatment modalities}

In total, 58 men and 49 women with a median age of 58 years were included. Among them, 93 patients (87\%) had MALT lymphoma, 5 (5\%) had high-grade transformed MALT lymphoma (renamed DLBCL with MALT lymphoma, DLBCL (MALT)), and 9 (8\%) had DLBCL. The orbit was the most commonly involved site
(49 patients, $46 \%$ ), followed by the conjunctiva (42 patients, $39 \%$ ) and lacrimal gland (16 patients, $15 \%$ ). Nighty-one patients had stage IE-IIE1 and 16 had stage IIE2-IVE disease (Table 1). The median age and distributions of sex, orbital laterality, primary lymphoma location, and lymphoma type did not differ between these 2 groups (stages IE-IIE1 vs. stages IIE2-IVE) (Table 1).

The treatment regimens are detailed in Table 2. Among the patients with stage IE-IIE1 disease, 26 received chemotherapy (20 MALT lymphoma, 1 DLBCL (MALT), and 5 DLBCL); 34 received radiotherapy (29 MALT lymphoma, 3 DLBCL (MALT), and 2 DLBCL); and 31 received other treatment modalities. The radiation prescription dose ranged from 30 to $50 \mathrm{~Gy}$ (median dose: 40 Gy) in daily fractions of 1.8-2.0 Gy. Chemotherapy or rituximab courses ranged from 2 to 8 cycles, and prophylactic granulocyte colony stimulating factor (G-CSF) was used on the basis of attending physicians' judgment. Among the patients who received other treatment modalities, 26 underwent surgery alone followed by observation, 4 received combined radiotherapy and chemotherapy, and 1 received intralesional rituximab injection. Among the patients with stage IIE2-IVE disease, 11 received chemotherapy and 5 received combined radiotherapy and chemotherapy.

\section{Treatment response and clinical outcome of patients with stage IE to IIE1 POALs}

Among the patients with stage IE-IIE1 POALs, the $\mathrm{CR}$ rates of those receiving chemotherapy, radiotherapy, and other treatment modalities were $87.5 \%, 91.2 \%$, and $67.8 \%$, respectively. Among the patients receiving chemotherapy, the $\mathrm{CR}$ rates of those receiving oral alkylating agents with or without rituximab, the cyclophosphamide, doxorubicin, vincristine, and prednisolone (CHOP)-based regimen, and the rituximab (R)-CHOP-based regimen were $87.5 \%$, $60.0 \%$, and $76.9 \%$, respectively (Figure 1) (Supplementary Table 1). During a median follow-up period of 54.7 months, 4 (4\%) of the 91 patients with stage I-IIE1 POALs experienced a relapse (Figure 2). One patient with conjunctival MALT lymphoma underwent first-line surgical excision. The patient had a local recurrence and underwent re-excision. Another patient with orbital DLBCL received first-line R-CHOP chemotherapy and had a retroperitoneal relapse. The patient then received a second-line regimen of rituximab, etoposide, methylprednisolone, high-dose cytarabine, and cisplatin and experienced CR. The other 2 patients had orbital MALT lymphoma; one received daily low-dose cyclophosphamide with rituximab, whereas the other received R-CHOP chemotherapy. They experienced a relapse in the central nervous system and received highdose methotrexate treatment to achieve CR in the brain.

The 5-year event-free survival (EFS) and overall survival (OS) rates of the patients with stage IE-IIE1 POALs were $88.6 \%$ and $92.5 \%$, respectively (Figure 3). 
Table 1: Comparison of the clinical characteristics of patients with stage IE-IIE1 or IIE2-IV POALs

\begin{tabular}{lccc}
\hline & Stage I-IIE1 & Stage IIE2-IV & \\
\hline Number of patients & 91 & 16 & 0.248 \\
Age at diagnosis & 57 & 65.5 & \\
$\quad$ Median & $22-102$ & $29-84$ & 0.872 \\
$\quad$ Range & 48 & 10 & \\
Sex & 43 & 6 & 0.904 \\
$\quad$ Male & & & \\
Female & 41 & 8 & \\
Orbital laterality & 34 & 4 & 0.980 \\
$\quad$ Right & 16 & 4 & \\
Left & & & \\
Bilateral & 40 & 9 & 0.468 \\
Location & 39 & 3 & \\
Orbital & 12 & 4 & \\
Conjunctiva & & 13 & \\
Lacrimal gland & 80 & 1 & \\
Pathology & 4 & 2 & \\
MALT lymphoma & 7 & & \\
DLBCL(MALT) & & & \\
DLBCL &
\end{tabular}

Abbreviations: POALs, primary ocular adnexal lymphomas; MALT, mucosa-associated lymphoid tissue; DLBCL, diffuse large B-cell lymphoma; DLBCL(MALT), DLBCL with histologic evidence of MALT lymphoma by WHO classification.
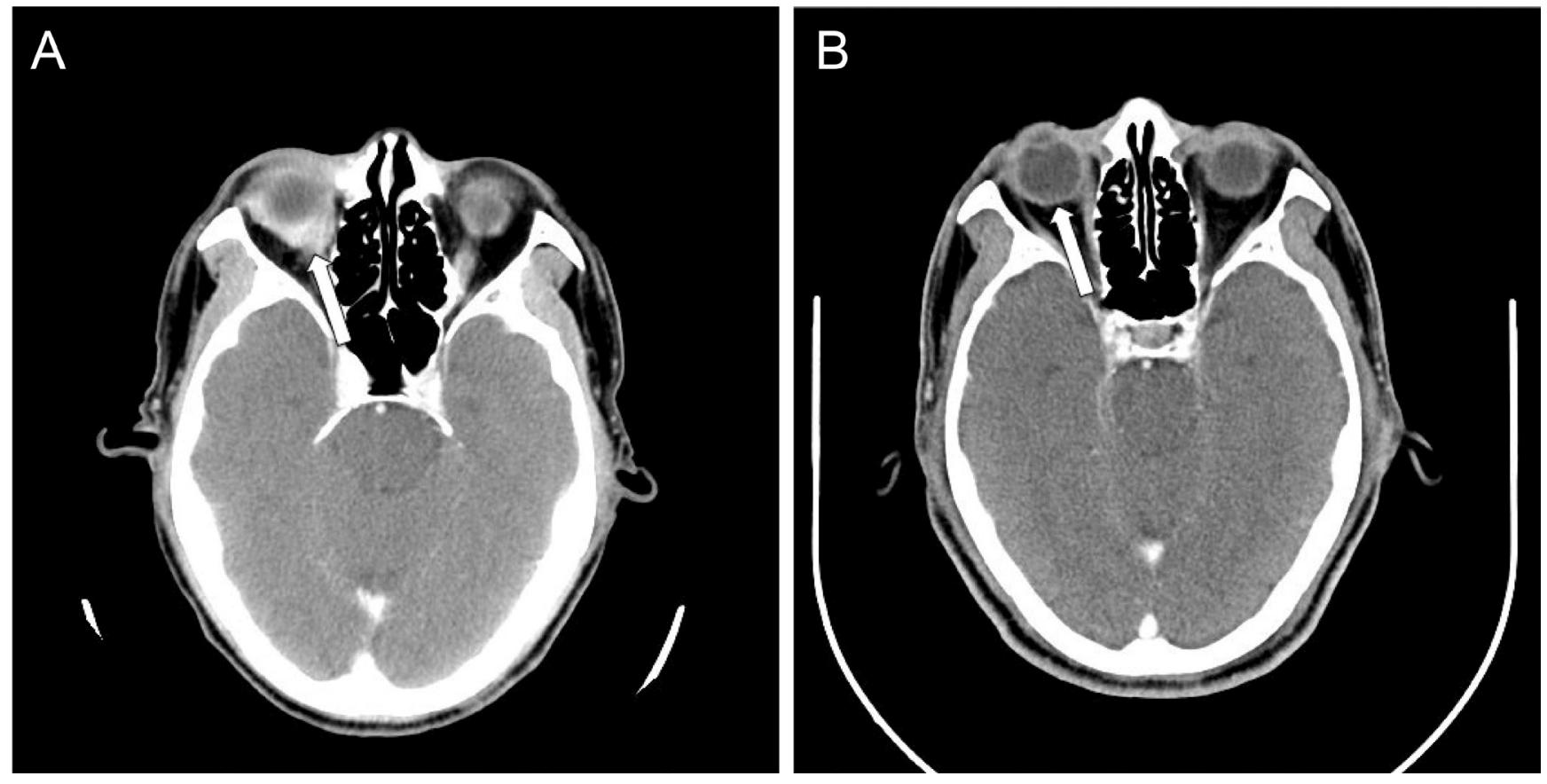

Figure 1: The CT scan of the brain with contrast showing (A) before treatment, the enhanced soft tissue infiltrates the right eyeball (arrow); and (B) after four cycles of R-CHOP, the tissue resolved with CR. 
Table 2: Treatment modalities of patients with stage IE-IIE1 and stage IIE2-IV POALs

\begin{tabular}{lc}
\hline & Number of patients \\
\hline Stage IE-IIE1 & \\
\hline Chemotherapy & 26 \\
Low-dose alkylating chemotherapy with/without rituximab & 8 \\
CHOP-based chemotherapy & 5 \\
R-CHOP-based chemotherapy & 13 \\
Radiotherapy & 34 \\
2D technique & 30 \\
3D conformational technique & 2 \\
Intensity-modulated radiotherapy & 1 \\
Volumetric modulated arc therapy & 1 \\
Other treatments & 31 \\
Surgery alone & 26 \\
Radiotherapy + low-dose alkylating chemotherapy with/without rituximab & 1 \\
Radiotherapy + CHOP-based chemotherapy & 2 \\
Radiotherapy + R-CHOP-based chemotherapy & 1 \\
Intralesional rituximab injection & 1 \\
\hline Stage IIE2-IV & \\
\hline Chemotherapy & 11 \\
Low-dose alkylating chemotherapy with/without rituximab & 5 \\
CHOP-based chemotherapy & 2 \\
R-CHOP-based chemotherapy & 4 \\
Combined chemotherapy and radiotherapy & 5 \\
Radiotherapy + low-dose alkylating chemotherapy with/without rituximab & 3 \\
Radiotherapy+ CHOP-based chemotherapy & 2 \\
\hline Abbrvition & \\
\hline
\end{tabular}

Abbreviations: POALs, primary ocular adnexal lymphomas; CHOP, cyclophosphamide, doxorubicin, vincristine, and prednisolone; R-CHOP, rituximab + CHOP.

Among patients with localized (stage I-IIE1) POALs, we found that the 5-year EFS rates of patients with MALT lymphoma, DLBCL (MALT), and DLBCL were 92.7\%, $50.0 \%$, and $80.0 \%$, respectively; the 5-year OS rates of the patients with MALT lymphoma, DLBCL (MALT), and DLBCL were $95.4 \%, 50.0 \%$, and $100 \%$, respectively. Because of the small number of patients with DLBCL (MALT), we divided localized patients into two subgroups, MALT lymphoma and DLBCL (also including DLBCL (MALT)). We found that patients with MALT lymphoma had a better 5-year EFS than those with DLBCL (including DLBCL (MALT); 92.7 vs. $64.8, P=0.05$ ). However, the OS was not different between these two subgroups (MALT lymphoma vs. DLBCL; $95.4 \%$ vs. $77.8 \%, P=0.176$ ).

Furthermore, among patients with stage IE-IIE1 POALs, the 5-year EFS rates of the patients with chemotherapy or rituximab-based immunochemotherapy, radiotherapy, and other treatment modalities were $90.0 \%$, $89.7 \%$, and $85.8 \%$, respectively; the 5-year OS rates of the patients with chemotherapy or rituximab-based immunochemotherapy, radiotherapy, and other treatment modalities were $100 \%, 90.4 \%$, and $87.5 \%$, respectively. The 5-year EFS and OS rates of the patients undergoing different chemotherapy regimens or rituximab-based immunochemotherapy are listed in Supplementary Table 1. Among patients with stage IE-IIE1 POALs, patients receiving systemic chemotherapy or rituximabbased immunochemotherapy had similar 5-year EFS $(P=0.489)$ and $\mathrm{OS}$ rates $(P=0.666)$ when compared with those receiving radiotherapy (Figure 4). Notably, patients with localized POALs who received an oral alkylating agent alone had a CR rate of $80 \%$, a 3 -year EFS of $100 \%$, and a 3 -year OS of $100 \%$.

\section{Treatment response and clinical outcome of patients with stage IE to IIE1 MALT lymphoma of POALs}

Because DLBCL is traditionally treated with chemotherapy or rituximab-based immunochemotherapy, we analyzed whether the efficacy of first-line systemic chemotherapy was the same as radiotherapy for localized MALT lymphoma when patients do not qualify for radiotherapy or when patients were afraid of potential long-term side effects of radiotherapy. The detailed information of the first-line treatment, including radiotherapy, chemotherapy or rituximab-based regimens of 80 patients with stage IE to IIE1 MALT lymphoma of 


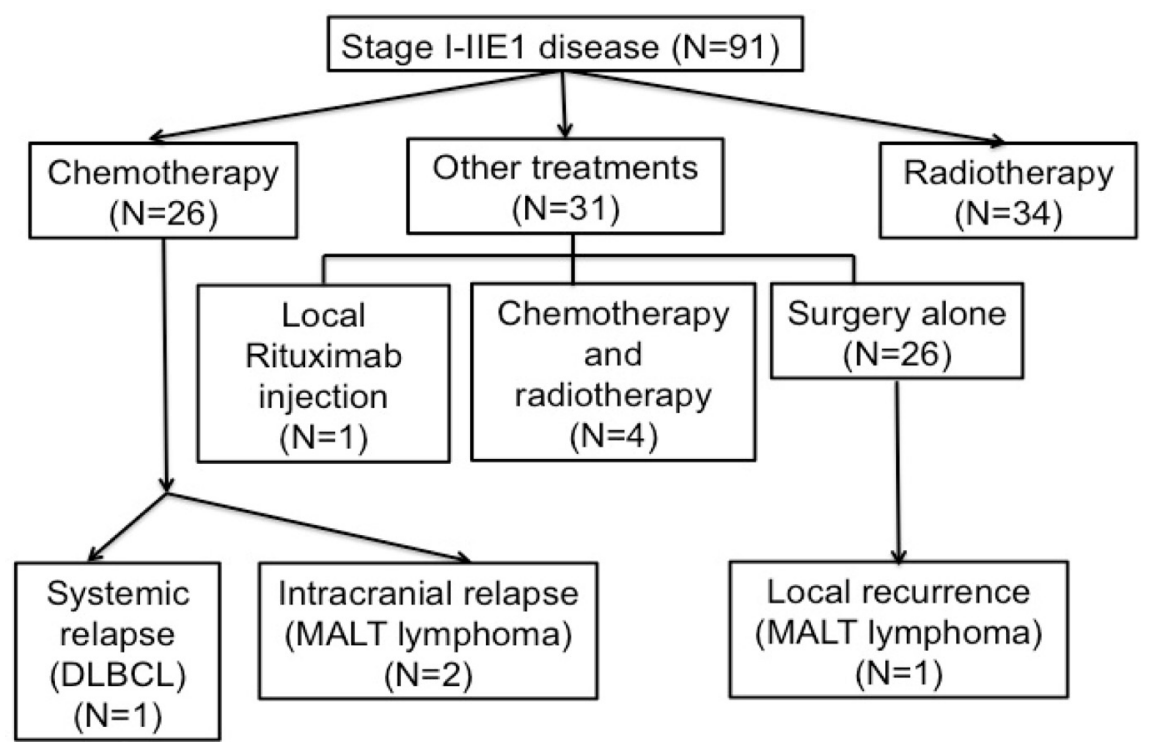

Figure 2: Flow diagram of patients with stage I-IIE1 primary ocular adnexal lymphoma. The patients are listed from intial treatment to disease relapse.
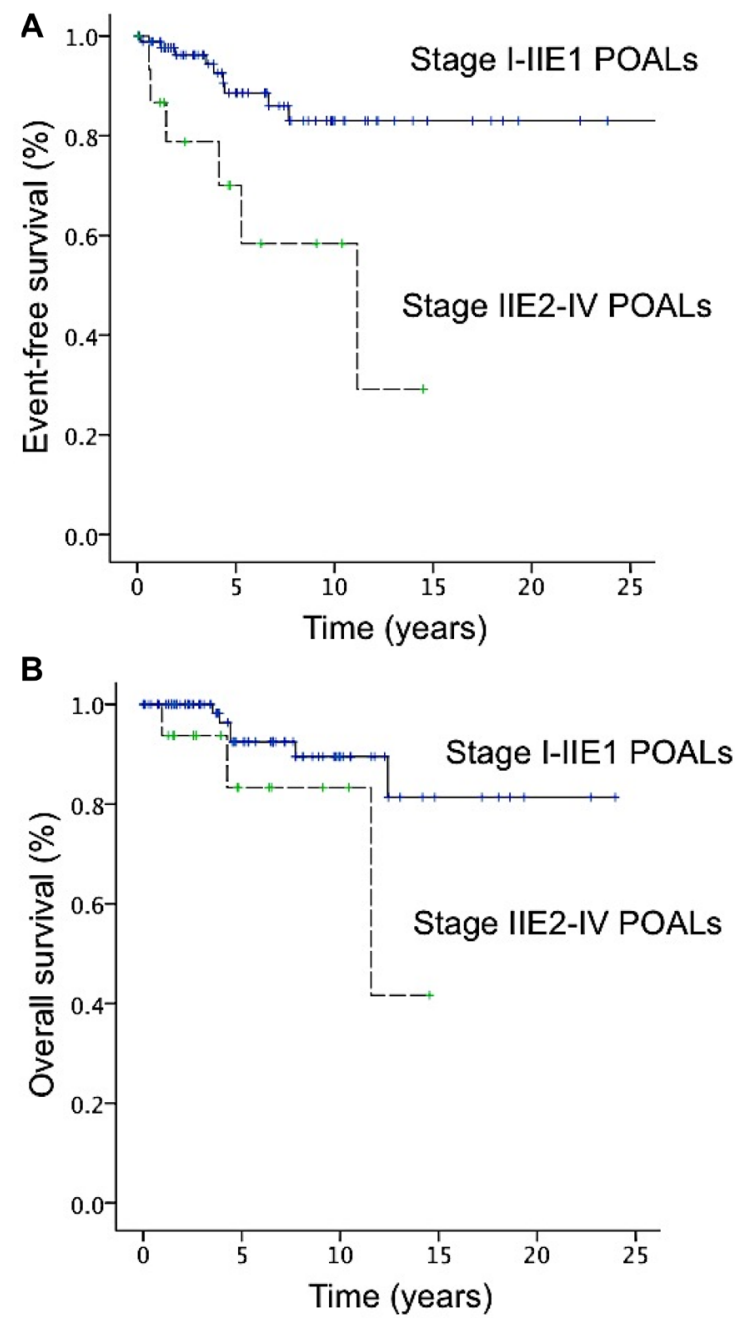

Figure 3: Curves of event-free surival (EFS) and overall survival (OS) of patients with primary ocular adnexal lymphoma. (A) The 5-year EFS rates for stage I-IIE1 and IIE2-IV disease were $88.6 \%$ and 70.0\%, respectively. (B) The 5-year OS rates for stage I-IIE1 and IIE2-IV disease were $92.5 \%$ and $83.3 \%$, respectively. 
Table 3: Univariate and multivariate analyses of event-free survival after frontline treatments in all patients with POALs

\begin{tabular}{lccc}
\hline \multicolumn{1}{c}{ Factors } & Relative risk & $\mathbf{9 5 \%} \mathbf{C l}$ & $\boldsymbol{P}$ value \\
\hline Univariate analysis & & & \\
$\quad$ Age $>$ 60 years & 3.720 & $1.184-11.691$ & $\mathbf{0 . 0 2 5}$ \\
Locations & 1 & & \\
$\quad$ Conjunctiva & 0.311 & $0.062-1.559$ & 0.155 \\
$\quad$ Orbital & 1.016 & $0.273-3.788$ & 0.981 \\
$\quad$ Lacrimal gland & 3.483 & $1.185-10.237$ & $\mathbf{0 . 0 2 3}$ \\
High-grade components & 3.281 & $1.357-10.759$ & $\mathbf{0 . 0 1 1}$ \\
LDH elevation & 4.293 & $1.464-12.590$ & $\mathbf{0 . 0 0 8}$ \\
Ann Arbor stage III-IV disease & 4.254 & $1.503-12.042$ & $\mathbf{0 . 0 0 6}$ \\
AJCC stage T3 and T4 disease & 5.191 & $1.608-16.764$ & $\mathbf{0 . 0 0 6}$ \\
AJCC stage with N1-4 disease & 2.538 & $0.715-9.012$ & 0.150 \\
AJCC stage with M1 disease & & & \\
Multivariate analysis & 4.441 & $1.133-17.400$ & $\mathbf{0 . 0 3 2}$ \\
Age $>$ 60 years &
\end{tabular}

Abbreviations: POALs, primary ocular adnexal lymphomas; CI, confidence interval; LDH, lactate dehydrogenase; AJCC, American Joint Committee on Cancer.

POALs are listed in Supplementary Table 2. We found that the CR rate for patients with radiotherapy, chemotherapy, and rituximab-based chemotherapy were $90 \%, 62.5 \%$, $83.3 \%$, respectively.

As shown in Supplementary Figure 1, we found that the 5-year EFS rate was not significantly different between patients receiving chemotherapy or rituximabbased immunochemotherapy and those receiving radiotherapy $(94.4 \%$ vs. $96.0 \%, P=0.250)$. In addition, the 5-year OS rate for patients receiving chemotherapy or rituximab-based immunochemotherapy and those receiving radiotherapy was $100 \%$ and $96.3 \%$, respectively $(P=0.511)$ (Supplementary Figure 1).

Nevertheless, among 26 patients with MALT lymphoma of POAL who underwent surgery alone, one developed a local recurrence after a follow-up period of 2.3 months; however, the remaining patients remained disease free after a follow-up period of up to 10 years.

\section{Treatment response and clinical outcome of patients with stage IIE2 to IV POALs}

The 5-year EFS and OS rates of the patients with stage IIE2-IV disease were $70.0 \%$ and $83.3 \%$, respectively. No significant differences were observed in the 5-year EFS $(61.7 \%$ vs $80.0 \%, P=0.388)$ or OS rates $(80.0 \%$ vs $80.0 \%, P=0.721)$ between patients receiving systemic chemotherapy or rituximab-based immunochemotherapy alone and those receiving systemic chemotherapy combined with local radiotherapy. The CR rate and 5-year EFS and OS rates of patients (all stages) receiving chemotherapy are listed according to the regimen in Supplementary Table 1.

\section{Prognostic factors}

In univariate analysis, an age $>60$ years $(P=0.025)$, high-grade lymphoma components $(P=0.23)$, increased serum LDH $(P=0.011)$, Ann Arbor stages III-IV $(P=0.008)$, and advanced American Joint Committee on Cancer (AJCC) TN stages (T3: preseptal eyelid involvement, T4: extending beyond the orbit to adjacent structures, $(P=0.006) ; \mathrm{N}$ : lymph node involvement $(P=0.006)$ were significantly associated with shorter EFS (Table 3 ). The primary lymphoma site (conjunctiva, orbital, or lacrimal gland), and advanced AJCC M stage were not associated with poor EFS (Table 3). An age $>60$ years was a characteristic finding for predicting poor EFS in multivariate analysis (Table 3 ). In addition, an age $>60$ years and Ann Arbor stages III-IV were significantly associated with poor OS in univariate and multivariate analyses (Table 4).

\section{Treatment-related side effects}

We analyzed acute and late toxicities in the chemotherapy (included rituximab-based immunochemotherapy) and radiotherapy groups. Among the 46 patients with chemotherapy, 17 received oral alkylating chemotherapy with or without rituximab and 29 received $\mathrm{CHOP}$ or R-CHOP-based regimens. No chemotherapy-related side effects were observed in the oral alkylating chemotherapy group. In the CHOP or R-CHOP chemotherapy group, 7 patients $(15.2 \%)$ had neutropenia, $2(4 \%)$ had anemia, and $6(13 \%)$ had increased liver enzymes. These acute side effects were manageable and reversible, and no secondary hematologic malignancy was reported during a follow-up period of 22.6 years. 
Table 4: Univariate and multivariate analyses of overall survival in all patients with POALs

\begin{tabular}{lccc}
\hline \multicolumn{1}{c}{ Factors } & Relative risk & $\mathbf{9 5 \%} \mathbf{C l}$ & $\boldsymbol{P}$ value \\
\hline Univariate analysis & & & \\
$\quad$ Age $>$ 60 years & 9.923 & $1.240-79.387$ & $\mathbf{0 . 0 3 1}$ \\
Locations & 1 & & \\
$\quad$ Conjunctiva & 0.140 & $0.012-1.604$ & 0.114 \\
$\quad$ Orbital & 0.901 & $0.174-4.677$ & 0.901 \\
$\quad$ Lacrimal gland & 3.021 & $0.748-12.200$ & 0.121 \\
High-grade components & 2.672 & $0.661-10.799$ & 0.168 \\
LDH elevation & 4.039 & $1.005-16.226$ & $\mathbf{0 . 0 4 9}$ \\
Ann Arbor stage III-IV disease & 3.169 & $0.779-12.895$ & 0.107 \\
AJCC stage T3 and T4 disease & 2.061 & $0.245-17.345$ & 0.506 \\
AJCC stage with N1-4 disease & 2.733 & $0.566-13.191$ & 0.211 \\
AJCC stage with M1 disease & & & \\
Multivariate analysis & 37.275 & $2.364-587.675$ & $\mathbf{0 . 0 1 0}$ \\
Age $>$ 60 years & 35.884 & $1.162-1108.528$ & $\mathbf{0 . 0 4 1}$ \\
$\quad$ Ann Arbor stage III-IV disease & & & \\
\hline Abbriati
\end{tabular}

Abbreviations: POALs, primary ocular adnexal lymphomas; CI, confidence interval; LDH, lactate dehydrogenase; AJCC, American Joint Committee on Cancer.

Among the 43 patients who received local radiotherapy, 11 had late ophthalmologic complications: $3(7 \%)$ had keratitis, $5(12 \%)$ had cataract, and $1(2 \%)$ had retinopathy. One patient had both keratitis and cataract, whereas another patient had both cataract and retinopathy. In addition, cataract was the most common late ophthalmological complication, occurring in 7 patients. Some patients received a total radiation dose of $50 \mathrm{~Gy}$, and lens shielding was not provided in early years, leading to retinopathy in 2 patients.

\section{DISCUSSION}

In this study, we observed that cytotoxic chemotherapy and chemotherapy combined with rituximab were effective in treating localized and disseminated POALs, most of which received a histological classification of MALT lymphoma. In this study, we reported that among patients with localized POALs (stage I-IIE1), low-dose oral alkylating agent alone had a CR rate of $80 \%$, a 3-year EFS of $100 \%$, and a 3 -year OS of $100 \%$. Considering that low-dose alkylating chemotherapy is less toxic than a combined chemotherapy regimen, such as CVP or CHOP, our results indicate that in addition to radiotherapy, lowdose alkylating chemotherapy alone can be an alternative first-line treatment for patients who are concerned about potential late ophthalmic complications of radiotherapy, or whose conditions are not suitable for radiotherapy.

Our results revealed that radiotherapy alone with a median dose of 40 Gy provided 5-year EFS and OS rates of $89.7 \%$ and $90.4 \%$, respectively, for patients with stage IE-IIE1 POALs. These findings are consistent with those of previous studies that reported that local radiotherapy of at least $30 \mathrm{~Gy}$ resulted in effective local control with 5-year progression-free survival (PFS) and OS rates of $65.5 \%-93.0 \%$ and $73.6 \%-100 \%$, respectively $[8-10,12,19,20]$. Some studies have reported an association of the histological evidence of MALT lymphoma with improved PFS and OS rates [19, 20]. However, the major late ophthalmological complications occurred with a radiotherapy dose of more than 30-35 Gy [21]. Our results and those of other studies have revealed that cataract, dry eye, and keratitis are the most common late radiotherapy-related adverse ophthalmological effects $[11,12]$. A decreased radiotherapy dose of 24-25 Gy and deployment of a lens shield can reduce late sequelae without compromising POALs treatment efficacy $[11,22]$. Fasola et al. reported that among 20 patients with POALs ( $95 \%$ were of the FL or MALT subtype), the administered low-dose radiotherapy ( 2 fractions of $2.0 \mathrm{~Gy}$ ) resulted in an overall response rate of $96 \%$ and 2-year local PFS of $100 \%$, without late ophthalmological complications [23]. In addition, the same low-dose radiotherapy ( 2 fractions of 2.0 Gy) provided a 2 year local PFS of $100 \%$ and a distant PFS of $68.6 \%$, but without the late complication of cataract in 7 patients with 8 lesions of POALs [24]. These findings indicate that low-dose radiotherapy can provide effective local control, with few late ophthalmological complications, whereas distant relapse should be considered when using low-dose radiotherapy for POALs.

Studies have examined the efficacy of different chemotherapy regimens in treating patients with localized POALs [13, 14, 25, 26]. For example, the administration of a single alkylating agent (chlorambucil) produced a 
CR rate of 79\% [13]. Moreover, combined CVP regimens provided a CR rate of $76.2 \%$ and a 5 -year PFS rate of $66 \%$ [14]. Rituximab alone exhibited moderate activity in treating POALs, particularly MALT lymphoma, with a CR rate of approximately $30 \%-50 \%$ and a median time to progression of 5 months [15-18]. In addition, some studies reported that prolonged administration of rituximab to 8 cycles or administration of rituximab for maintenance can increase the treatment response rate [27, 28]. Rigacci et al reported that when rituximab was combined with chlorambucil, the CR rate increased to $89 \%$ in low-grade POALs [29]. Compared to local radiotherapy for localized POALs, Mino et al and Paik et al also reported that chemotherapy, rituximab alone, or immunochemotherapy is an effective treatment for MALT-POAL [28, 30]. We observed a CR rate of $76.9 \%$ and a 5 -year OS rate of $66.7 \%$ in 13 patients with stage I-IV POAL after the administration of an oral alkylating agent with or without rituximab; these rates are consistent with the results of Rigacci et al [29].

In the present study, we analyzed the $\mathrm{CR}$ rate and the clinical outcomes of a total of 37 patients who received chemotherapy or rituximab-based immunochemotherapy. Among patients with localized POALs, we found that the $\mathrm{CR}$ rate and the 5-year EFS and OS were not different between patients receiving chemotherapy or rituximabbased immunochemotherapy (rituximab alone or rituximab plus chemotherapy) and those receiving radiotherapy.
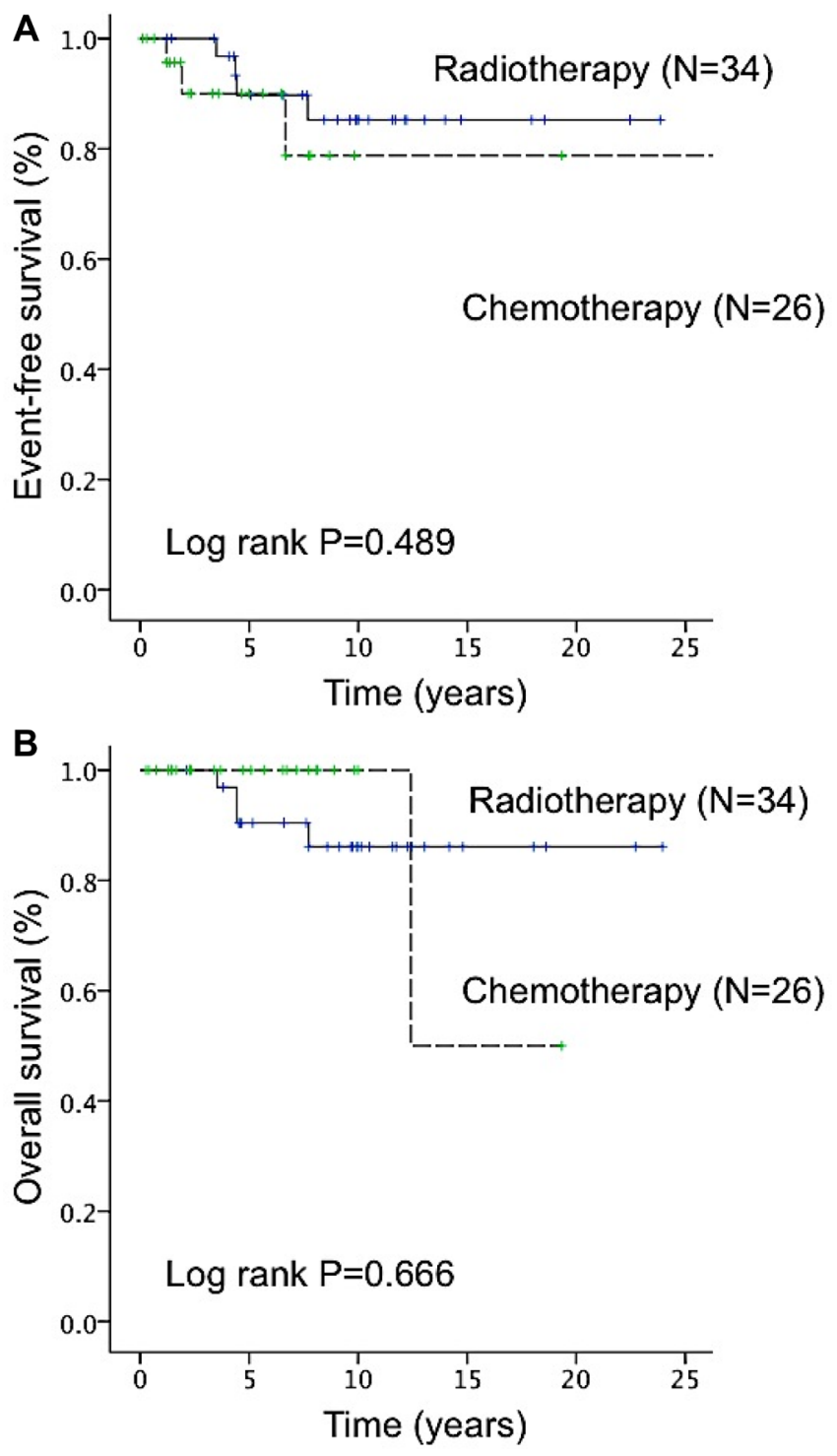

Figure 4: Difference in event-free survival (EFS) and overall survival (OS) between radiotherapy and chemotherapy (included rituximab-based immunochemotherapy) in patients with stage IE-IIE1 primary ocular adnexal lymphoma.

(A) The 5-year EFS rate did not significantly differ between patients who underwent radiotherapy and those who underwent chemotherapy or rituximab-based immunochemotherapy $(89.7 \%$ vs $90.0 \%, P=0.489)$. (B) The 5-year OS rate did not significantly differ between patients who underwent radiotherapy and those who underwent chemotherapy or rituximab-based immunochemotherapy $(90.4 \%$ vs $100.0 \%$, $P=0.666)$. 
Although the number of enrolled patients was small, most of our patients received oral alkylating agents (chlorambucil) or rituximab-based immunochemotherapy and had long-term follow-up. Because most patients with localized POALs are treated with radiotherapy, there were very few patients receiving systemic chemotherapy as first-line treatment. However, for patients who cannot receive radiotherapy or did not respond to radiotherapy, an alternative treatment with similar efficacy and fewer side effects, such as chemotherapy or rituximab-based immunochemotherapy is necessary. Combining our results and that of 10 other investigators (Table 5), a CR was achieved in $80 \%$ of patients with stage IE-IIE1 MALT lymphoma who received chlorambucil and in $83.3 \%$ of patients who received rituximab-based regimens. Kiesewetter et al. also reported that among 16 patients with stage IE-IIE1 POALs, immunochemotherapy regimens (included lenalidomide, bortezomib, oxaliplatin, CHOP, rituximab, or rituximab-based regimens) resulted in $81.3 \%$ overall response rate ( 9 cases, CR; 4 cases, partial remission [PR]) [31]. These findings indicate that in addition to radiotherapy, chemotherapy or rituximab-based regimen is an effective treatment strategy for patients with localized POALs, including those with MALT lymphoma histology.

Although the fluorine 18 fluoro-deoxyglucose positron emission tomography (FDG-PET) provides more precise staging for lymphoma, computed tomography (CT) or magnetic resonance imaging (MRI) provided higher sensitivity than FDG-PET for local ocular adnexal lesions of POALs. For example, English et al. demonstrated that FDG-PET detected systemic diseases more reliably than CT scan alone, whereas FDG-PET was less sensitive than CT scan for detecting localized POALs [32]. In addition, Zanni et al. revealed that among patients with POALs, especially those with non-conjunctival sites of lymphoma, the sensitivity of FDG-PET was lower than that of MRI scan in the assessment of POALs [33]. Considering that $85 \%$ of our patients had localized disease (stage I-IIE1), whole-body CT scan, including orbital MRI, at initial staging is adequate, although only 5 of our 91 localized POAL patients underwent FDG-PET. However, we cannot exclude the possibility that a proportion of our patients with localized POALs (stage IE-IIE1) may be re-staged to stage IIE2-IV diseases if FDG-PET was incorporated as an initial staging method.

Zucca et al investigated prognostic factors for patients with nongastric MALT lymphoma in a retrospective study. They reported that Ann Arbor stage IV was a prognostic factor for poor OS, whereas classifying patients into groups of intermediate to high risk on the basis of international prognostic index scores had a negative influence on PFS in multivariate analysis [34]. Martinet et al revealed that among patients with POALs who received radiotherapy, a young age and lowgrade lymphoma were associated with improved OS and disease-free survival in multivariate analysis [35]. In the multivariate analyses, we found that an age $>60$ years was an independently poor prognostic factor for EFS, whereas elevation of LDH, and stages III-IV lost significances in EFS. In addition, an age $>60$ years and Ann Arbor stages III-IV were significantly associated with poor OS. Our findings are lined with a retrospective analyses of 182 patients with MALT lymphoma of POALs (80\% of them were stage I) reporting that an age $>60$ years was independently associated with the shorter progression-free survival [36]. Meunier et al. also showed that age greater than 59 years was significantly associated with poor OS for ophthalmologic and intraocular NHL populations in the multivariate analysis [37]. However, the precise mechanism responsible for the poorer prognosis in older patients with POALs remains to be clarified. Studies using the TNM system to evaluate the prognosis of POALs reported an association of $\mathrm{T} 3, \mathrm{~T} 4, \mathrm{~N}$, and $\mathrm{M}$ stages with poor outcomes [38-40]. However, an advanced TNM stage of POALs did not affect the prognosis in our cohort.

Our study had some limitations. First, it was a retrospective study, and some patients did not strictly follow the treatment protocols. Second, the study was conducted between 1990 and 2015, and improved radiation techniques may affect outcomes and reduce side effects. However, we provided long-term favorable outcomes by using systemic chemotherapy alone to treat localized or disseminated POALs. Furthermore, we observed that among our patients with stage IE POALs, lymphoma can be cured after complete resection alone as only $1(5.5 \%)$ of our 18 patients developed local relapse, suggesting that close observation without adjuvant treatment after complete resection is another option for localized POALs.

In terms of the similar EFS and OS, our findings indicated that for patients with localized MALT lymphoma of POALs, the first-line chemotherapy is an effectively alternative treatment for patients who can't receive radiotherapy. In a recent retrospective analysis of 142 patients with stage I MALT lymphoma of POALs, Desai A et al. reported that 22 of 111 patients (108 with CR) receiving first-line radiotherapy alone developed local or systemic relapse, whereas 2 of 7 patients (all with CR) treated with chemotherapy alone had local or systemic relapse [36]. In their study, the prescribed radiotherapy dose $\geq 30.6$ Gy was associated with better CR rate and progression-free survival. This is consistent with our study showing radiotherapy alone with a median dose of 40 Gy provided 5-year EFS and OS rates of $89.7 \%$ and $90.4 \%$, respectively.

In conclusion, our results demonstrated that systemic chemotherapy alone provided favorable outcomes in patients with localized and disseminated POAL. For patients with localized MALT-POAL, low-dose oral alkylating chemotherapy with or without rituximab is as effective as more intensive regimens. In addition, radiotherapy or surgery can also efficiently control local disease in localized MALT-POAL. Old age and stages 
Table 5: Summary of treatment outcomes after chemotherapy in patients with POALs

\begin{tabular}{|c|c|c|c|c|c|c|}
\hline Studies & $\begin{array}{c}\text { Patient } \\
\text { no. }\end{array}$ & Stage & $\begin{array}{c}\text { Histology } \\
\text { types }\end{array}$ & Regimens & $\begin{array}{l}\text { Treatment } \\
\text { response }\end{array}$ & Survival \\
\hline $\begin{array}{l}\text { Ben Simon, } \\
\text { et al. [13] }\end{array}$ & 33 & IE & $\begin{array}{c}\text { MALT } \\
\text { lymphoma }\end{array}$ & Chlorambucil & $\begin{array}{c}26(79 \%): \mathrm{CR} \\
7(21 \%): \mathrm{PR}\end{array}$ & \\
\hline Song, et al. [14] & 21 & I-IIE & $\begin{array}{l}\text { MALT } \\
\text { lymphoma }\end{array}$ & CVP & $\begin{array}{c}16(76 \%): \mathrm{CR} \\
5(24 \%): \mathrm{PR}\end{array}$ & $\begin{array}{c}\text { 5-year PFS: } \\
66 \%\end{array}$ \\
\hline Nückel, et al. [15] & 2 & IE & $\begin{array}{c}\text { MALT } \\
\text { lymphoma }\end{array}$ & Rituximab & $\begin{array}{l}1(50 \%): \mathrm{CR} \\
1(50 \%): \mathrm{PR}\end{array}$ & \\
\hline Ferreri, et al. [16] & 8 & IE: 4, IV: 4 & $\begin{array}{c}\text { MALT } \\
\text { lymphoma }\end{array}$ & Rituximab & $\begin{array}{c}3(37.5 \%): \mathrm{CR} \\
2(25 \%): \mathrm{PR}\end{array}$ & \\
\hline Tuncer, et al. [17] & 10 & IE & $\begin{array}{c}\text { MALT } \\
\text { lymphoma: 9; } \\
\text { FL: } 1\end{array}$ & Rituximab & $\begin{array}{l}5(50 \%): \mathrm{CR} \\
5(50 \%): \mathrm{PR}\end{array}$ & \\
\hline Sokol, et al. [18] & 2 & IE & $\begin{array}{c}\text { MALT } \\
\text { lymphoma }\end{array}$ & Rituximab & $\begin{array}{l}1(50 \%): \mathrm{CR} \\
1(50 \%): \mathrm{PR}\end{array}$ & $\begin{array}{c}\text { 5-year PFS: } \\
100 \%\end{array}$ \\
\hline Annibal, et al. [27] & 6 & IE & $\begin{array}{l}\text { MALT } \\
\text { lymphoma }\end{array}$ & Rituximab & $\begin{array}{l}4(67 \%): \mathrm{CR} \\
2(33 \%): \mathrm{PR}\end{array}$ & \\
\hline Mino, et al. [28] & 10 & I-IIE & $\begin{array}{c}\text { MALT } \\
\text { lymphoma }\end{array}$ & Rituximab & 10 (100\%):CR & \\
\hline Rigacc, et al. [29] & 9 & IE: 8, IV: 1 & $\begin{array}{c}\text { MALT } \\
\text { lymphoma: } 8 ; \\
\text { FL:1 }\end{array}$ & $\begin{array}{l}\text { Rituximab+ } \\
\text { chlorambucil }\end{array}$ & $\begin{array}{l}8(89 \%): C R \\
1(11 \%): P R\end{array}$ & \\
\hline Paik, et al. [30] & 9 & $\begin{array}{l}\text { I-IIE: } 7 \\
\text { IVE: } 2\end{array}$ & $\begin{array}{c}\text { MALT } \\
\text { lymphoma }\end{array}$ & $\begin{array}{l}\text { CVP, CHOP, R-CVP, } \\
\text { R-CHOP }\end{array}$ & 9 (100\%):CR & \\
\hline Present study & 20 & I-IIE1 & $\begin{array}{c}\text { MALT } \\
\text { lymphoma }\end{array}$ & $\begin{array}{c}\text { Total: } 20 \\
\text { Chlorambucil: } 5 \\
\text { Rituximab-based: } 12 \\
\text { CHOP: } 3\end{array}$ & $\begin{array}{c}15(75 \%): \mathrm{CR} \\
4(80 \%): \mathrm{CR} \\
10(83 \%): \mathrm{CR} \\
1(33.3): \mathrm{CR}\end{array}$ & $\begin{array}{c}\text { 5-year EFS: } \\
94.4 \% \\
\text { 5-year OS: } \\
100 \%\end{array}$ \\
\hline
\end{tabular}

Abbreviations: POALs, primary ocular adnexal lymphomas; MALT, mucosa-associated lymphoid tissue; FL, follicular lymphoma; DLBCL (MALT): diffuse large B-cell lymphoma with histologic evidence of MALT lymphoma; CVP, cyclophosphamide, vincristine, and prednisolone; CHOP, cyclophosphamide, vincristine, doxorubicin, prednisolone; R-CVP, rituximab, cyclophosphamide, vincristine, and prednisolone; R-CHOP, rituximab, cyclophosphamide, vincristine, doxorubicin, prednisolone; CR, complete remission; PR, partial remission; PFS, progression-free survival.

III-IV were the most critical prognostic factors for OS. Other cytotoxic chemotherapies such as fludarabine and bendamustine have exhibited efficacy in treating MALT lymphoma [41-43]. Additional studies are required to analyze different combinations of treatment modalities for minimizing long-term toxicity and improving outcomes in patients with poor prognostic factors.

\section{MATERIALS AND METHODS}

\section{Clinical pathological features and treatment modalities}

Patients diagnosed with POALs between January 1990 and December 2015 were retrospectively reviewed. The pretreatment evaluation involved history taking, comprehensive physical examination, complete blood cell count analysis, blood chemistry analysis (including lactate dehydrogenase $[\mathrm{LDH}]$ ), bone marrow studies, a wholebody CT scan, or MRI for orbital lesions. Since 2006, FDGPET has been used for aggressive lymphoma staging in our institution. However, the FDG-PET scan in staging of low-grade lymphoma, including MALT lymphoma, is not covered by health insurance. Among 54 patients diagnosed after 2006, 14 patients (26\%) underwent FDG-PET for initial staging. The patients with POALs were divided into the following 2 groups on the basis of their disease staging according to the modified Ann Arbor staging [39, 44]. Considering bilateral ocular adnexal lesions of lymphoma and adjacent lymphatics involvement could be treated by local irradiation, the localized POAL (stage IE to IIE1) was defined as a lymphoma involving unilateral ocular adnexal 
lesions with adjacent lymphatics, or bilateral ocular adnexal lesions with adjacent lymphatics in this study. If primary lesions involved ocular adnexal lesions and nonadjacent lymphatics (i.e. above the diaphragm), we defined them as stage IIE2 POALs. Patients with stage IE-IIE1 disease who received frontline radiotherapy, chemotherapy, rituximab-based immunochemotherapy, or other treatments were included in this retrospective study, whereas those who were treated with first-line antibiotics (including doxycycline) were excluded.

Among the patients with stage IE-IIE1 disease belonging to the radiotherapy-alone group, most patients were treated with a 6-MV photon beam for POALs of the orbit, extraocular muscle, eyelids, lacrimal gland, or conjunctiva. However, some received a $6-20-\mathrm{MeV}$ electron beam for conjunctival lesions. Of the patients,
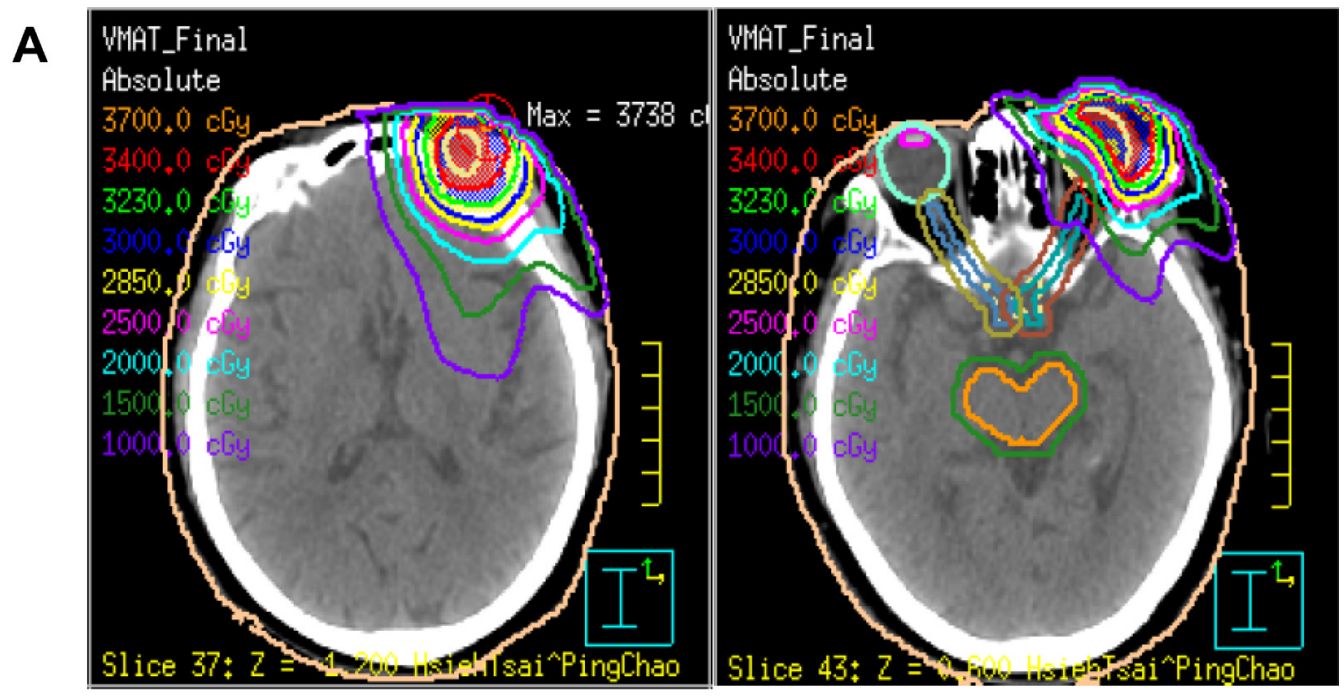

B

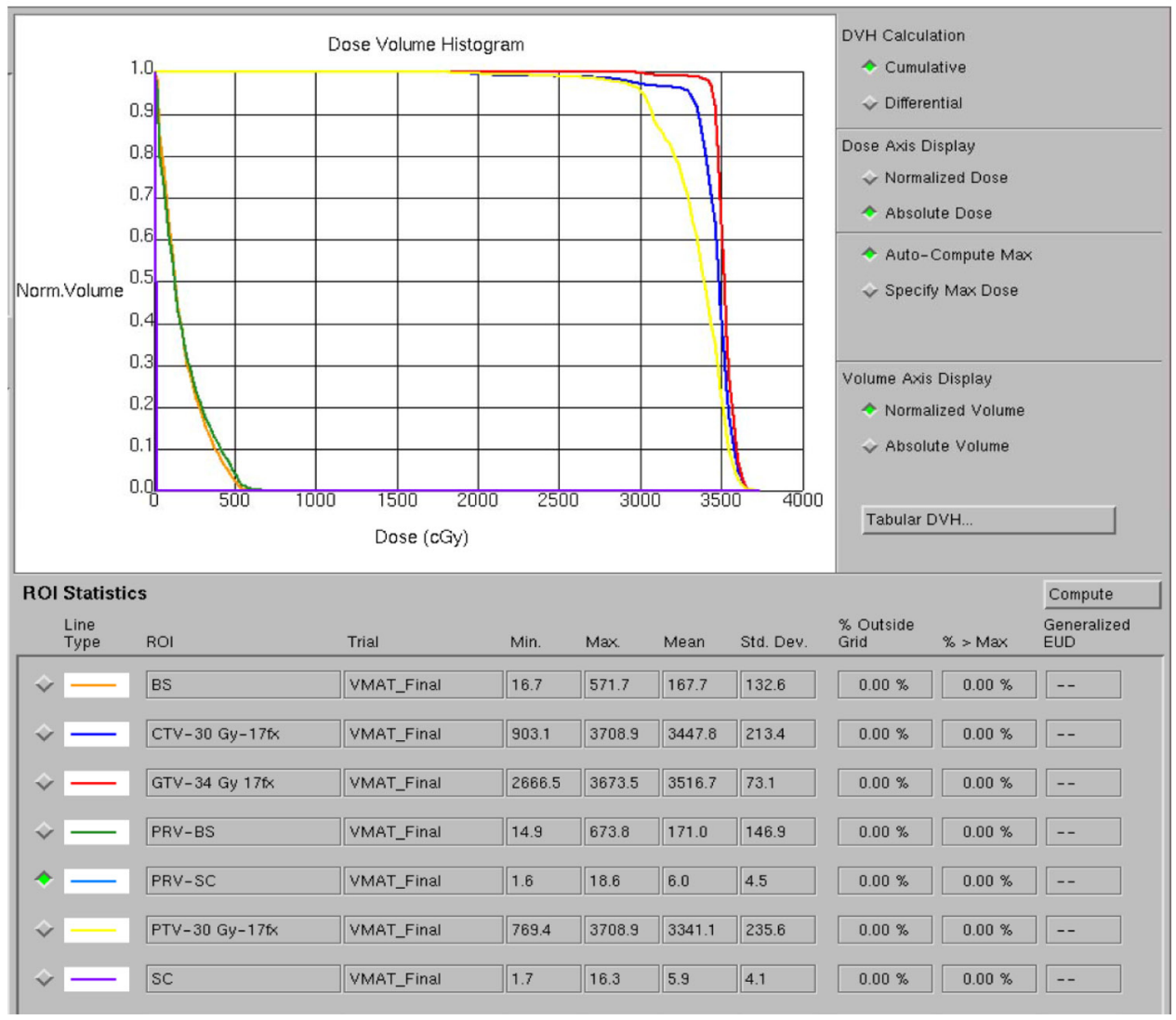

Figure 5: Isodose curves (A) and a dose-volume histogram (B) of the volumetric-modulated arc therapy plan using coplanar and noncoplanar beam arrangements displayed on the axial plane. The radiation prescription dose was 34 Gy (3400 cGy) in daily fractions of 2.0 Gy for one 79-year-old woman with left orbital MALT lymphoma. Abbreviations: GTV, gross target volume; CTV, clinical target volume; PTV, planning target volume. BS, brain stem; SC, spinal cord. 
30 underwent 2-dimensional radiotherapy; 2 received a 3-dimensional conformal technique; 1 underwent intensitymodulated radiotherapy; and 1 underwent volumetricmodulated arc therapy (Figure 5) (Table 2). The radiation prescription dose ranged from 30 to 50 Gy (median dose: $40 \mathrm{~Gy}$ ) in daily fractions of 1.8-2.0 Gy.

The patients with stage IE-IIE1 disease in the systemic treatment group were treated with 3 chemotherapy protocols: (1) daily low-dose cyclophosphamide or chlorambucil with or without rituximab $\left(375 \mathrm{mg} / \mathrm{m}^{2}\right.$ of rituximab administered every 3-4 wk); (2) cyclophosphamide, doxorubicin, vincristine, and prednisolone (CHOP)-based regimens (the dose of doxorubicin was lowered or omitted on the basis of the attending physicians' judgment); and (3) R-CHOPbased chemotherapy (CHOP plus $375 \mathrm{mg} / \mathrm{m}^{2}$ of rituximab administered every 3-4 wk). Other treatment modalities are listed in Table 2.

Patients with stage IIE2-IVE disease were treated with systemic chemotherapy with or without rituximab or in combination with radiotherapy. The types of chemotherapy regimens and radiation doses were similar to those for the patients with stage IE-IIE1 disease.

\section{Evaluation and ethic statements}

Previous studies evaluating the responses to radiotherapy or chemotherapy for POALs were based on the clinical, radiologic, and pathologic criteria according to the international response criteria for malignant lymphoma [27, 28, 30, 45]. Because POALs are irregularly shaped and the tumors are not centrally located, one ocular lesion (which may involve the eye and both adjacent ocular walls), it is difficult to measure the tumor volume. Some studies suggest that the application of the Response Evaluation Criteria in Solid Tumors (RECIST) and RECIST 1.1 for assessing the treatment response of POALs is valuable $[31,46,47,48]$.

In the present study, the treatment response was assessed based on the primary location of the POALs, which was divided into two subgroups, conjunctival lesions and non-conjunctival lesions. All patients received regular ophthalmologic local examination and a physical examination every 2 to 3 months, and follow-up CT examinations or MRI examinations every 3 months after starting treatment. For conjunctival lesions of POALs, a complete remission (CR) was defined as the complete absence of clinical evidence of lymphoma on slit-lamp examination for at least 6 weeks, whereas a partial response (PR) was defined as a disease reduction of at least $50 \%$ for 6 weeks [49]. For non-conjunctival lesions of POALs, the assessment of tumor response was according to the Response Evaluation Criteria in Solid Tumors (RECIST) and RECIST 1.1 [31, 46, 47].

The study protocol was approved by the Research Ethics Committee of National Taiwan University Hospital (NTUH: 201505013RIND). The patients' medical data were anonymized prior to the access and analysis. The Research Ethics Committee waived the need for written informed consent from the patients because all potential patientidentifying information was removed prior to data analysis.

\section{Statistical analysis}

The discrete variables of the patients with stage IE-IIE1 and IIE2-IVE POALs were compared using the chi-square test or Fisher exact test. If continuous data were not normally distributed, Mann-Whitney $U$ tests were used to compare continuous variables and medians of distributions. Event-free survival (EFS) after the first-line treatment was calculated from the date of initial treatment until treatment failure, including disease progression, relapse, or treatment discontinuation for any reason, including death. Overall survival (OS) was calculated from the date of initial treatment to the date of death from any cause $[45,50]$. A $P$ value of $<0.05$ was considered statistically significant.

\section{ACKNOWLEDGMENTS AND FUNDING}

The authors thank the Cancer Registry, Office of Medical Records, National Taiwan University Hospital, for providing necessary patient information. This study was supported by research grants MOST 104-2314-B-002189-MY3 and MOST 105-2811-B-002-041 from the Ministry of Science and Technology, Taiwan, MOHW106TDU-B-211-113002 from the Ministry of Health and Welfare, and NTUH 106-S3514 and 106-N3691 from National Taiwan University Hospital.

\section{CONFLICTS OF INTEREST}

The authors declare no conflicts of interest.

\section{REFERENCES}

1. Fitzpatrick PJ, Macko S. Lymphoreticular tumors of the orbit. Int J Radiat Oncol Biol Phys. 1984; 10:333-340.

2. Moslehi R, Devesa SS, Schairer C, Fraumeni JF Jr. Rapidly increasing incidince of ocular non-Hodgkin lymphoma. J Natl Cancer Inst. 2006; 98:936-939.

3. Coupland SE, Krause L, Delecluse HJ, Anagnostopoulos I, Foss HD, Hummel M, Bornfeld N, Lee WR, Stein H. Lymphoproliferative lesions of the ocular adnexa. analysis of 112 cases. Ophthalmology. 1998; 105:1430-1441.

4. Ferry JA, Fung CY, Zukerberg L, Lucarelli MJ, Hasserjian RP, Preffer FI, Harris NL. Lymphoma of the ocular adnexa: a study of 353 cases. Am J Surg Pathol. 2007; 31:170-184.

5. Kiesewetter B, Raderer M. Antibiotic therapy in nongastrointestinal MALT lymphoma: a review of the literature. Blood. 2013; 122:1350-1357. 
6. Ferreri AJ, Dolcetti R, Magnino S, Doglioni C, Ponzoni M. Chlamydial infection: the link with ocular adnexal lymphomas. Nat Rev Clin Oncol. 2009; 6:658-669.

7. Stannard C, Sauerwein W, Maree G, Lecuona K. Radiotherapy for ocular tumours. Eye (Lond). 2013; 27:119-127.

8. Bhatia S, Paulino AC, Buatti JM, Mayr NA, Wen BC. Curative radiotherapy for primary orbital lymphoma. Int J Radiat Oncol Biol Phys. 2002; 54:818-823.

9. Hasegawa M, Kojima M, Shioya M, Tamaki Y, Saitoh J, Sakurai H, Kitamoto Y, Suzuki Y, Niibe H, Nakano T. Treatment results of radiotherapy for malignant lymphoma of the orbit and histopathologic review according to the WHO classification. Int J Radiat Oncol Biol Phys. 2003; 57:172-176.

10. Fung CY, Tarbell NJ, Lucarelli MJ, Goldberg SI, Linggood RM, Harris NL, Ferry JA. Ocular adnexal lymphoma: clinical behavior of distinct World Health Organization classification subtypes. Int J Radiat Oncol Biol Phys. 2003; 57:1382-1391.

11. Goda JS, Le LW, Lapperriere NJ, Millar BA, Payne D, Gospodarowicz MK, Wells W, Hodgson DC, Sun A, Simpson R, Tsang RW. Localized orbital mucosa-assocaited lymphoma tissue lymphoma managed with primary radiation therapy: efficacy and toxicity. Int J Radiat Oncol Biol Phys. 2011; 81:e659-666.

12. Kaushik M, Pulido JS, Schild SE, Stafford S. Risk of radiation retinopathy in patients with orbital and ocular lymphoma. Int J Radiat Oncol Biol Phys. 2012; 84:1145-1150.

13. Ben Simon GJ, Cheung N, McKelvie P, Fox R, McNab AA. Oral chlorambucil for extranodal, marginal zone, B-cell lymphoma of mucosa-associated lymphoid tissue of the orbit. Ophthalmology. 2006; 113:1209-1213.

14. Song EK, Kim SY, Kim TM, Lee KW, Yun T, Na II, Shin H, Lee SH, Kim DW, Khwarg SI, Heo DS. Efficacy of chemotherapy as a first-line treatment in ocular adnexal extranodal marginal zone B-cell lymphoma. Ann Oncol. 2008; 19:242-246.

15. Nückel H, Meller D, Steuhl KP, Dührsen U. Anti-CD20 monoclonal antibody therapy in relapsed MALT lymphoma of the conjunctiva. Eur J Haematol. 2004; 73:258-262.

16. Ferreri AJ, Ponzoni M, Martinelli G, Muti G, Guidoboni M, Dolcetti R, Doglioni C. Rituximab in patients with mucosalassociated lymphoid tissue-type lymphoma of the ocular adnexa. Haematologica. 2005; 90:1578-1579.

17. Tuncer S, Tanyıldız B, Basaran M, Muyukbabani N, Dogan O. Systmeic rituximab immunotherapy in the management of primary ocular adnexal lymphoma: single institution experience. Curr Eye Res. 2015; 40:780-785.

18. Sokol JA, Landau L, Lauer SA. Rituximab immunotherapy for ocular adnexal lymphoma: clinicopathologic correlation with 5-year follow-up. Ophthal Plast Reconstr Surg. 2009; 25:322-4.

19. Son SH, Choi BO, Kim GW, Yang SW, Hong YS, Choi IB, Kim YS. Primary radiaiton therapy in patients with locallized orbital marginal zone B-cell lymphoma of mucosa-associated lymphoid tissue (MALT Lymphoma). Int J Radiat Oncol Biol Phys. 2010; 77:86-91.

20. Parikh RR, Moskowitz BK, Maher E, Della Rocca D, Della Rocca R, Culliney B, Shapira I, Grossbard ML, Harrison LB, Hu K. Long-term outcomes and patterns of failure in orbital lymphoma treated with primary radiotherapy. Leuk Lymphoma. 2015; 56:1266-1270.

21. Stafford SL, Kozelsky TF, Garrity JA, Kurtin PJ, Leavitt JA, Martenson JA, Habermann TM. Orbital lymphoma: radiotherapy outcome and complications. Radiother Oncol. 2001; 59:139-144.

22. Tran KH, Campbell BA, Fua T, MacManus M, Ryan G, Chesson B, Wirth A. Efficacy of low dose radiotherapy for primary orbital marginal zone lymphoma. Leuk Lymphoma. 2013; 54:491-496.

23. Fasola CE, Jones JC, Huang DD, Le QT, Hoppe RT, Donaldson SS. Low-dose radiation therapy $(2 \mathrm{~Gy} \times 2)$ in the treatment of orbital lymphoma. Int J Radiat Oncol Biol Phys. 2013; 86:930-935.

24. König L, Stade R, Rieber J, Debus J, Herfarth K. Radiotherapy of indolent orbital lymphomas : Two radiation concepts. Strahlenther Onkol. 2016; 192:414-421.

25. Munch-Petersen HD, Rasmussen PK, Coupland SE, Esmaeli B, Finger PT, Graue GF, Grossniklaus HE, Honavar SG, Khong JJ, McKelvie PA, Mulay K, Prause JU, Ralfkiaer E, et al. Ocular adenxal diffuse large B-cell lymphoma: a multicenter international study. JAMA Ophthalmol. 2015; 133:165-173.

26. Rasmussen PK, Coupland SE, Finger PT, Graue GF, Grossniklaus HE, Honavar SG, McKelvie P, Mulay K, Prause JU, Ralfkiaer E, Sjö LD, Heegaard S. Ocular adenxal follicular lymphoma: a multicenter international study. JAMA Ophthalmol. 2014; 132:851-858.

27. Annibali O, Chiodi F, Sarlo C, Cortes M, QuarantaLeoni FM, Quattrocchi C, Bianchi A, Bonini S, Avvisati G. Rituximab as Single Agent in Primary MALT Lymphoma of the Ocular Adnexa. Biomed Res Int. 2015; 2015:895105.

28. Mino T, Mihara K, Yoshida T, Takihara Y, Ichinohe T. Monthly administration of rituximab is useful for patients with ocular adnexal mucosa-associated lymphoid tissue lymphoma. Blood Cancer J. 2014; 4:e245.

29. Rigacci L, Nassi L, Puccioni M, Mappa S, Polito E, Dal Pozzo S, Alterini R, Carrai V, Puccini B, Bosi A. Rituximab and chlorambucil as first-line treatment for low-grade ocular adnexal lymphomas. Ann Hematol. 2007; 86:565-568.

30. Paik JS, Cho WK, Lee SE, Choi BO, Jung SE, Park GS, Kim SH, Yang SW, Cho SG. Ophthalmologic outcomes after chemotherapy and/or radiotherapy in non-conjunctival ocular adnexal MALT lymphoma. Ann Hematol. 2012; 91:1393-401.

31. Kiesewetter B, Lukas J, Kuchar A, Mayerhoefer ME, Streubel B, Lagler H, Müllauer L, Wöhrer S, Fischbach J, Raderer M. Clinical features, treatment and outcome of 
mucosa-associated lymphoid tissue (MALT) lymphoma of the ocular adnexa: single center experience of 60 patients. PLoS One. 2014; 9:e104004.

32. English JF, Sullivan TJ. The Role of FDG-PET in the diagnosis and staging of ocular adnexal lymphoproliferative disease. Orbit. 2015; 34:284-291.

33. Zanni M, Moulin-Romsee G, Servois V, Validire P, Bénamor M, Plancher C, Rouic LL, Dendale R, VincentSalomon A, Asselain B, Sahli R, Decaudin D. Value of 18FDG PET scan in staging of ocular adnexal lymphomas: a large single-center experience. Hematology. 2012; 17:76-84.

34. Zucca E, Conconi A, Pedrinis E, Cortelazzo S, Motta T, Gospodarowicz MK, Patterson BJ, Ferreri AJ, Ponzoni M, Devizzi L, Giardini R, Pinotti G, Capella C, et al. Nongastric marginal zone B-cell lymphoma of mucosaassociated lymphoid tissue. Blood. 2003; 101:2489-2495.

35. Martinet S, Ozsahin M, Belkacémi Y, Landmann C, Poortmans P, Oehlere C, Scandolaro L, Krengli M, Maingon P, Miralbell R, Studer G, Chauvet B, Marnitz S, et al. Outcome and prognostic factors in orbital lymphoma: a Rare Cancer Network study on 90 consecutive patients treated with radiotherapy. Int J Radiat Oncol Biol Phys. 2003; 55:892-898.

36. Desai A, Joag MG, Lekakis L, Chapman JR, Vega F, Tibshirani R, Tse D, Markoe A, Lossos IS. Long-term course of patients with primary ocular adnexal MALT lymphoma: a large single-institution cohort study. Blood. 2017; 129:324-332.

37. Meunier J, Lumbroso-Le Rouic L, Vincent-Salomon A, Dendale R, Asselain B, Arnaud P, Fourquet A, Desjardins L, Plancher C, Validire P, Chaoui D, Lévy C, Decaudin D. Ophthalmologic and intraocular non-Hodgkin's lymphoma: a large single centre study of initial characteristics, natural history, and prognostic factors. Hematol Oncol. 2004; 22:143-158.

38. Aronow ME, Portell CA, Rybicki LA, Sweetenham JW, Singh AD. Ocular Adnexal Lymphoma: Assessment of a Tumor-Node-Metastasis Staging System. Ophthalmology. 2013; 120:1915-1919.

39. Graue GF, Finger PT, Maher E, Della Rocca D, Della Rocca R, Lelli GJ Jr, Milman T. Ocular adnexal lymphoma staging and treatment: American Joint Committee on Cancer versus Ann Arbor. Eur J Ophthalmol. 2013; 23:344-355.

40. Rath S, Connors JM, Dolman PJ, Rootman J, Rootman DB, White VA. Comparison of American Joint Committee on Cancer TNM-based Staging System (7th edition) and Ann Arbor Classification for Predicting Outcome in Ocular Adnexal Lymphoma. Orbit. 2014; 33:23-28.
41. Zinzani PL, Stefoni V, Musuraca G, Tani M, Alinari L, Gabriele A, Marchi E, Pileri S, Baccarani M. Fludarabinecontaining chemotherapy as frontline treatment of nongastrointestinal mucosa-associated lymphoid tissue lymphoma. Cancer. 2004; 100:2190-2194.

42. Salar A, Domingo-Domenech E, Estany C, Canales MA, Gallardo F, Servitje O, Fraile G, Montalbán C. Combination therapy with rituximab and intravenous or oral fludarabine in the first-line, systemic treatment of patients with extranodal marginal zone B-cell lymphoma of the mucosa-associated lymphoid tissue type. Cancer. 2009; 115:5210-5217.

43. Kiesewetter B, Mayerhoefer ME, Lukas J, Zielinski CC, Müllauer L, Raderer M. Rituximab plus bendamustine is active in pretreated patients with extragastric marginal zone B cell lymphoma of the mucosa-associated lymphoid tissue (MALT lymphoma). Ann Hematol. 2014; 93:249-253.

44. Rohatiner A, d'Amore F, Coiffier B, Crowther D, Gospodarowicz M, Isaacson P, Lister TA, Norton A, Salem P, Shipp M, Somers R. Report on a workshop convened to discuss the pathological and staging classifications of gastrointestinal tract lymphoma. Ann Oncol. 1994; 5:397-400.

45. Cheson BD, Pfistner B, Juweid ME, Gascoyne RD, Specht L, Horning SJ, Coiffier B, Fisher RI, Hagenbeek A, Zucca E, Rosen ST, Stroobants S, Lister TA, et al. Revised response criteria for malignant lymphoma. J Clin Oncol. 2007; 25:579-86.

46. Eisenhauer EA, Therasse P, Bogaerts J, Schwartz LH, Sargent D, Ford R, Dancey J, Arbuck S, Gwyther S, Mooney M, Rubinstein L, Shankar L, Dodd L, et al. New response criteria in solid tumours: revised RECIST guideline (version 1.1). Eur J Cancer. 2009; 45:228-247.

47. Wahl RL, Jacene H, Kasamon Y, Lodge MA. From RECIST to PERCIST: evolving consideration for PET response criteria in solid tumors. J Nucl Med. 2009; 50:122S-150S.

48. Guffey Johnson J, Terpak LA, Margo CE, Setoodeh R. Extranodal marginal zone B-cell lymphoma of the ocular adnexa. Cancer Control. 2016; 23:140-149.

49. Blasi MA, Tiberti AC, Valente P, Laguardia M, Sammarco MG, Balestrazzi A, Larocca LM, Balestrazzi E. Intralesional interferon- $\alpha$ for conjunctival mucosaassociated lymphoid tissue lymphoma: long-term results. Ophthalmology. 2012; 119:494-500.

50. Kuo SH, Yeh KH, Chen LT, Lin CW, Hsu PN, Hsu C, Wu MS, Tzeng YS, Tsai HJ, Wang HP, Cheng AL. Helicobacter pylori-related diffuse large B-cell lymphoma of the stomach: a distinct entity with lower aggressiveness and higher chemosensitivity. Blood Cancer J. 2014; 4:e220. 